Article

\title{
Numerical Simulation on the Influence of the Longitudinal Fins on the Enhancement of a Shell-and-Tube Ice Storage Device
}

\author{
Pei Cai ${ }^{1}$, Youxue Jiang ${ }^{2}$, He Wang ${ }^{3}$, Liangyu Wu ${ }^{4}$, Peng Cao ${ }^{4}$, Yulong Zhang ${ }^{5, *}$ \\ and Feng Yao ${ }^{1,3, *}$ \\ 1 School of Environmental Science and Engineering, Suzhou University of Science and Technology, \\ Suzhou 215009, China; pcai@microflows.net \\ 2 Jiangsu Vocational Institute of Commerce, Nanjing 211168, China; yxjiang2019@aliyun.com \\ 3 School of Energy and Environment, Southeast University, Nanjing 210096, China; hwang@microflows.net \\ 4 College of Electrical, Energy and Power Engineering, Yangzhou University, Yangzhou 225127, China; \\ lywu@yzu.edu.cn (L.W.); pcao@microflows.net (P.C.) \\ 5 Pen-Tung Sah Institute of Micro-Nano Science and Technology, Xiamen University, Xiamen 361005, China \\ * Correspondence: zy198@xmu.edu.cn (Y.Z.); yaofeng@usts.edu.cn (F.Y.)
}

Received: 23 February 2020; Accepted: 14 March 2020; Published: 15 March 2020

\begin{abstract}
The theoretical model of the solidification process of a shell-and-tube ice storage (STIS) device with longitudinal fins is established. The liquid fraction, the energy-discharging rate and the ice storage ratio are investigated, with particular focus on the effects of the fin structure parameters on the solidification process. Furthermore, the temperature and the streamline distributions are discussed to reveal the mechanism of the solidification process in the STIS device and the negative effect of natural convection (NC). It is indicated that the solidification process of the STIS device is dominated by the heat transfer via the fins at the beginning, and then by the heat transfer at the water-ice interface. The ice storage is negatively affected by the NC, for the reason that the water with a higher temperature stays in the lower part of the STIS device and the temperature gradient at the water-ice interface is small. The ice storage performance can be enhanced by increasing the fin structure parameters, including height, thickness and number.
\end{abstract}

Keywords: ice storage; natural convection; heat transfer; solidification

\section{Introduction}

There is often an imbalance in time or space between energy supply and energy demand in living and engineering applications [1-3]. For example, the energy load in urban areas varies more than $30 \%$ between day and night, which leads to lots of energy waste [4-6]. To fix these problems, thermal energy storage systems are attracting more attention [7-9]. With phase change materials (PCMs) they can absorb energy in the evening and regenerate the thermal energy in the daytime, which fills the gap of the energy load between day and night $[10,11]$. Among the various thermal energy storage system types, the so-called cold energy storage system using water as PCMs, which is also known as the ice storage system, has been utilized in applications such as advanced energy systems [12,13], food cold chain [14], peak load shifting [15] and building air conditioning systems [16].

The main challenge for the utilization of the ice storage system is the low heat conductivity of PCMs $[17,18]$. Therefore, several enhancement methods have been taken for the improvement of the ice storage system, including fins [19], metal foam [20], microcapsules [21,22], nanoparticles [23] and heat pipes [24,25]. Inspired by natural fractal geometry, Zhang et al. [19] improved the energy-discharging rate, utilizing fractal fins for the latent heat device. The magnetic liquid could also significantly 
improve the heat transfer performance of the annular system with fins [4]. Among the above devices, the shell-and-tube ice storage (STIS) device with fins is the most commonly used, due to its excellent manufacturability $[26,27]$. There is available literature about the role of fin structure parameters in system improvements [28,29]. For the economic and optimized design of the STIS device with fins, it is urgent to comprehensively evaluate which fin structure parameter is the most effective one to enhance the ice storage performance.

There is literature that shows that the natural convection (NC) negatively affects the solidification process of the STIS device [30,31]. To weaken the NC, several attempts have been made [32], such as metal foam [33,34], multitube [35] and fins [36]. Internal and external fins were added on a latent energy storage unit by Pathak et al. [4], and the NC was found to be effectively weakened. However, for the STIS device with longitudinal fins, it is still unclear which fin structure parameter is the most useful for weakening the NC.

In this study, the two-dimensional enthalpy-porosity model of an STIS device with longitudinal fins is established and verified by experimental results with an STIS unit. The solidification phenomenon is simulated to reveal the solidification heat transfer mechanism, considering the NC. The effects of the fin structure parameters on the solidification process are discussed. The current study provides a deep understanding of the solidification process of an STIS device with longitudinal fins and a guideline for the parameter selection of the STIS device with longitudinal fins.

\section{Mathematical Model}

In this work, the theoretical model of the STIS device is established to analyze the role the longitudinal fins on the cold thermal energy storage performance of the STIS device. The STIS device is a circular shell-and-tube tank with longitudinal fins equally spaced, shown in Figure 1. The geometrical parameters of the STIS device are shown in Table 1. The water in the tank with a thermal insulated shell is frozen by the working fluid. The initial temperatures of the longitudinal fins and water in the STIS device are both $10^{\circ} \mathrm{C}$. The temperatures of the inner wall of the tube and the working fluid in the tube are constant at $-4^{\circ} \mathrm{C}$. The velocity of the water is initially zero.

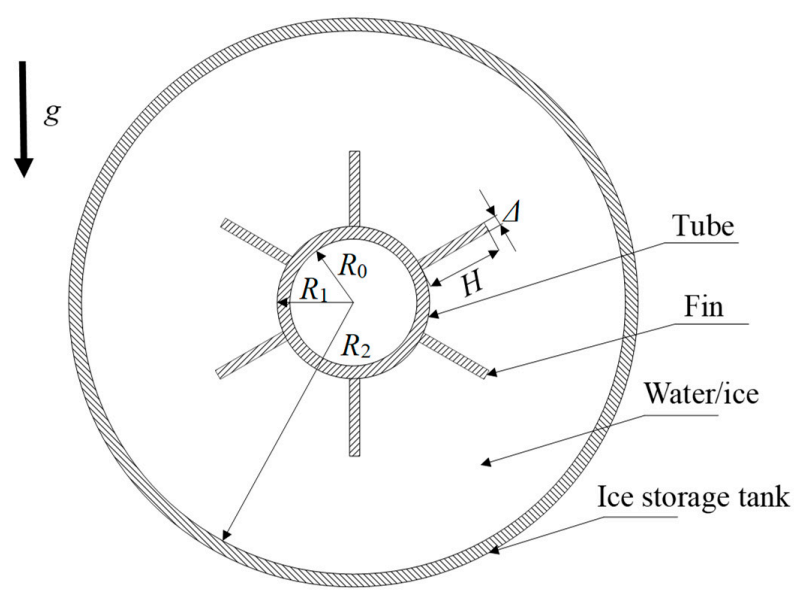

Figure 1. Schematic of the shell-and-tube ice storage (STIS) device.

Table 1. The geometrical parameters.

\begin{tabular}{ccc}
\hline Parameter & Description & Dimensions \\
\hline$R_{0}(\mathrm{~mm})$ & Tube inner radius & 20 \\
$R_{1}(\mathrm{~mm})$ & Tube outer radius & 25 \\
$R_{2}(\mathrm{~mm})$ & Shell radius & 85 \\
$H(\mathrm{~mm})$ & Fin height & $20,30,40$ \\
$\Delta(\mathrm{mm})$ & Fin thickness & $1,3,5$ \\
$N$ & Fin number & $6,8,10$ \\
\hline
\end{tabular}


The presumptions of this model are made as follows:

(1) Only laminar flow is considered in this simulation;

(2) The materials of the equipment, including water, ice, shell, tube and fin are isotropic;

(3) The physical parameters, except density of the water, are constant throughout this work;

(4) There is considered to be a local equilibrium of temperature and heat flux between water and fins [37].

\subsection{Governing Equations}

To simulate the solidification process of the STIS device, the enthalpy-porosity method [38] is applied. The equation of the mass conservation is:

$$
\frac{\partial \rho}{\partial t}+\frac{\partial(\rho u)}{\partial x}+\frac{\partial(\rho v)}{\partial y}=0
$$

The momentum equations are expressed as:

$$
\begin{aligned}
& \rho\left(\frac{\partial u}{\partial t}+u \frac{\partial u}{\partial x}+v \frac{\partial u}{\partial x}\right)=\mu\left(\frac{\partial^{2} u}{\partial x^{2}}+\frac{\partial^{2} u}{\partial y^{2}}\right)-\frac{\partial p}{\partial x}+S_{x} \\
& \rho\left(\frac{\partial v}{\partial t}+u \frac{\partial v}{\partial x}+v \frac{\partial v}{\partial x}\right)=\mu\left(\frac{\partial^{2} v}{\partial x^{2}}+\frac{\partial^{2} v}{\partial y^{2}}\right)-\frac{\partial p}{\partial y}+S_{y}
\end{aligned}
$$

where $\mu$ is the water viscosity, $t$ is the time of this simulation, $p$ is the pressure, and $u$ and $v$ are the water velocities along the $x$ and $y$ axes, respectively [39]. The density of the water $\rho$ is a temperature-dependent parameter and will be discussed later. The source terms $S_{\mathrm{x}}$ and $S_{\mathrm{y}}$ are calculated by

$$
\begin{gathered}
S_{x}=\frac{(1-\beta)^{2}}{\left(\beta^{3}+\omega\right)} A_{m} u \\
S_{y}=\frac{(1-\beta)^{2}}{\left(\beta^{3}+\omega\right)} A_{m} v+\frac{\rho g \delta\left(h-h_{\text {ref }}\right)}{c}
\end{gathered}
$$

where the mixture region constant value $A_{m}=10^{8} \mathrm{~kg} /\left(\mathrm{m}^{3} \cdot \mathrm{s}\right)$ [40], $g$ is the gravity acceleration, $\omega$ is a small constant value to avoid singularity and $h_{\text {ref }}$ is the enthalpy for the reference state. The mushy zone constant measures the amplitude of the damping. The higher this value, the steeper the transition of the velocity of the water to zero as it solidifies. The enthalpy $h$ is:

$$
h=h_{\mathrm{ref}}+\int_{T_{\mathrm{ref}}}^{T} c d T
$$

where $T_{\text {ref }}$ is the temperature for the reference state.

The volume fraction of liquid $\beta$ is:

$$
\beta= \begin{cases}1 & T \geq T_{m} \\ 0 & T<T_{m}\end{cases}
$$

where $T_{\mathrm{m}}$ is the freezing temperature of the water.

The specific heat for the computational domain at constant pressure $c$ is:

$$
c=c_{s}+\beta\left(c_{1}-c_{s}\right)
$$

where $c_{\mathrm{S}}$ is the specific heat of the ice and $c_{1}$ is the specific heat of the water. 
The energy equation is expressed as:

$$
\frac{\partial(\rho h)}{\partial t}+\frac{\partial(\rho h u)}{\partial x}+\frac{\partial(\rho h v)}{\partial y}=\nabla \cdot(\alpha \Delta h)-S_{h}
$$

where $\alpha=\lambda / \rho c$ is the thermal diffusivity. The source term $S_{\mathrm{h}}$ is calculated by:

$$
S_{h}=\frac{\partial(\rho \Delta H)}{\partial t}
$$

where $\Delta H$ is the latent heat, and:

$$
\Delta H= \begin{cases}L & T \geq T_{m} \\ 0 & T<T_{m}\end{cases}
$$

where $L$ is the melting latent heat for the ice.

The thermal conductivity $\lambda$ is:

$$
\lambda=\lambda_{s}+\beta\left(\lambda_{1}-\lambda_{s}\right)
$$

where $\lambda_{\mathrm{s}}$ and $\lambda_{1}$ are the heat conductivities of the ice and water, respectively.

Since the effect of NC is considered in this study, following the Boussinesq assumption, the temperature-dependent $\rho$ is

$$
\rho=\rho_{0}\left(1-\gamma\left|T-T_{0}\right|\right)
$$

where $\rho_{0}=999.972 \mathrm{~kg} / \mathrm{m}^{3}, \gamma=9.297173 \times 10^{-6}$ and $T_{0}=4.02935^{\circ} \mathrm{C}$.

\subsection{Numerical Solutions}

Using FLUENT 6.3, the governing equations for the two-dimensional ice solidification process in the STIS device are solved. The QUICK scheme is a high-order differencing scheme, which can be used to solve Equations (2), (3) and (9) in the present model. The iteration in each time step stops once the average residual of the temperature is below one millionth. Based on the independence test for the time-step, the time-step $0.01 \mathrm{~s}$ is used for the simulation. According to the grid independence test and computation cost evaluation, 20,740 meshes are applied.

\subsection{Model Validation}

The numerical simulation of the ice storage process is compared with experimental ice freezing process to verify the accuracy of the present model. In the validation experiment, the tube with eight fins $(H=50 \mathrm{~mm}, \Delta=5 \mathrm{~mm})$ is made of alumina and placed in a transparent plastic chamber. The chamber is wrapped by polyurethane to avoid losing cold energy to the external environment. The chamber is filled with water, of which the initial temperature is $4{ }^{\circ} \mathrm{C}$. The chiller (XODC-2030-II) is used to provide the working fluid with the constant temperature $-10^{\circ} \mathrm{C}$. The ice-water interface is captured by a Charge-coupled device (CCD) Camera (DFK 23U274). The blue region represents the solid phase. As shown in Figure 2a, the ice-water interface evolution in the numerical calculation shows agreement with the experiments, so that this theoretical model is capable of predicting the solidification process. The time evolution of the ice storage ratio is shown in Figure $2 b$. The ice storage ratio is the ratio of the volume of frozen water to the total volume of water in the STIS device. The ice storage ratio $\eta$ is the ratio of the volume of frozen water to the total volume of water in the STIS device. The relative error between the simulation and the experiment is less than $10 \%$, which can be explained by the effect of the experimental system, for example the heat leakage and the contact thermal resistance. 

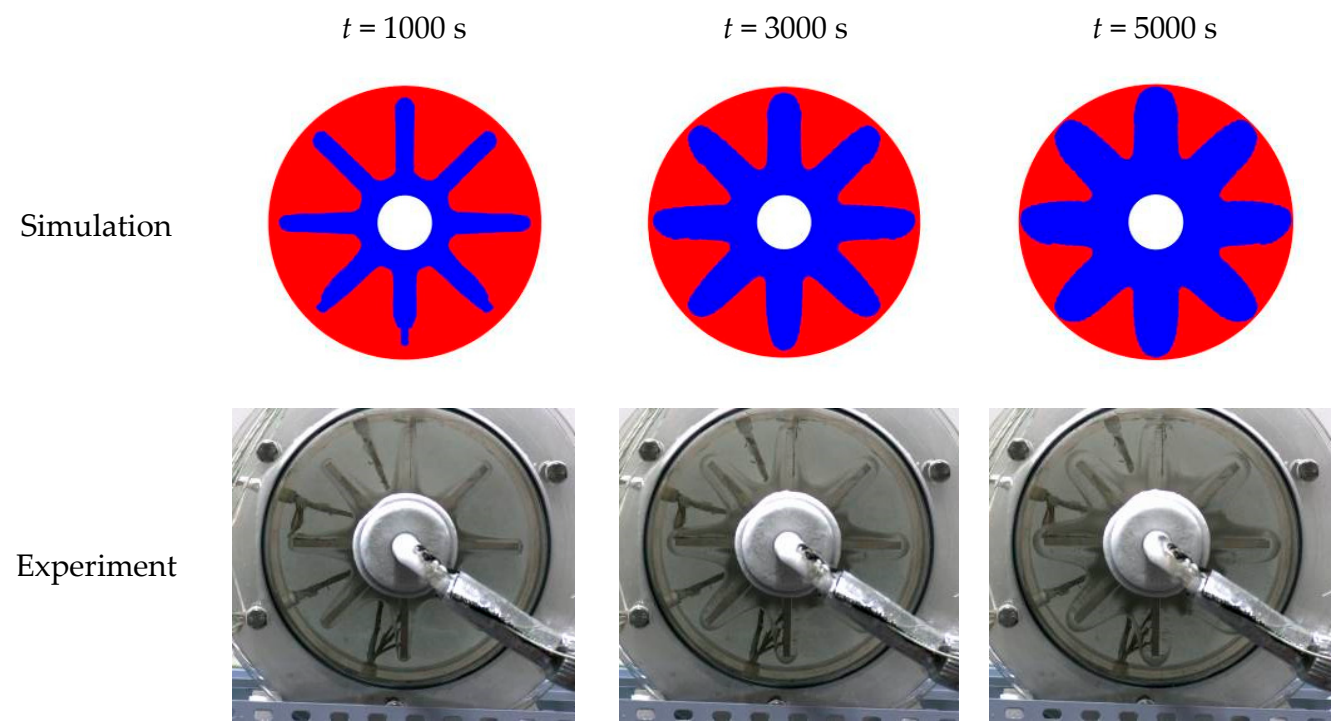

(a)

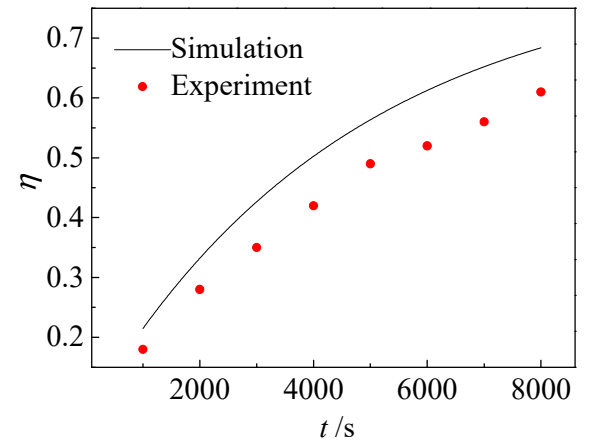

(b)

Figure 2. Comparison of the ice storage process in the STIS device with longitudinal fins between the simulation and the experiment: (a) ice front; (b) ice storage ratio.

\section{Results and Discussion}

To investigate the enhancement by the longitudinal fins, the solidification process of water is numerically simulated. The ice-water interface and temperature distribution is investigated to obtain the effects of fin structure parameters on the solidification process, including the height, the thickness and the number.

\subsection{Solidification Process}

To give a basic description on the phenomena of the solidification process in the present model, Figure 3 illustrates the contours of the volume fraction of liquid and the temperature in the STIS device with the six fins $(H=30 \mathrm{~mm}, \Delta=3 \mathrm{~mm})$. The solidification processes with the NC and without the NC are compared in Figure 3. The ice initially forms near the tube and the fins. The ice layer grows thicker with time, leading to a larger thermal resistance of the ice. Therefore, the weakened heat transfer leads to the slower ice formation. Without the NC, both the contours of the liquid fraction and the temperature are vertically symmetrical. However, the water with a higher temperature is heavier and moves downwards in the STIS device, which is attributed to the NC. Furthermore, the smaller temperature difference between the ice and water near the interface makes the solidification 
phenomenon retarded. Therefore, with NC, the solidification of the water is slower and there is more ice in the upper part of the STIS device.

(a)

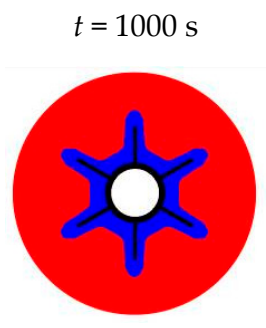

(b)

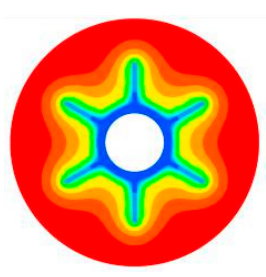

(c)

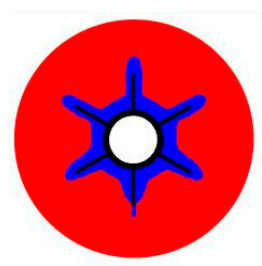

(d)

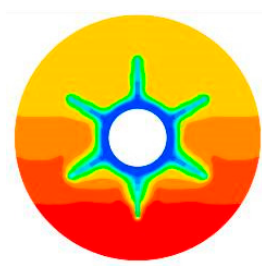

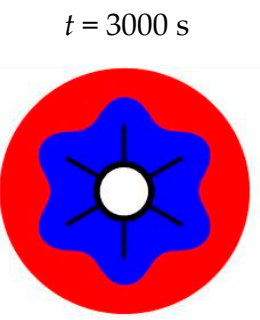
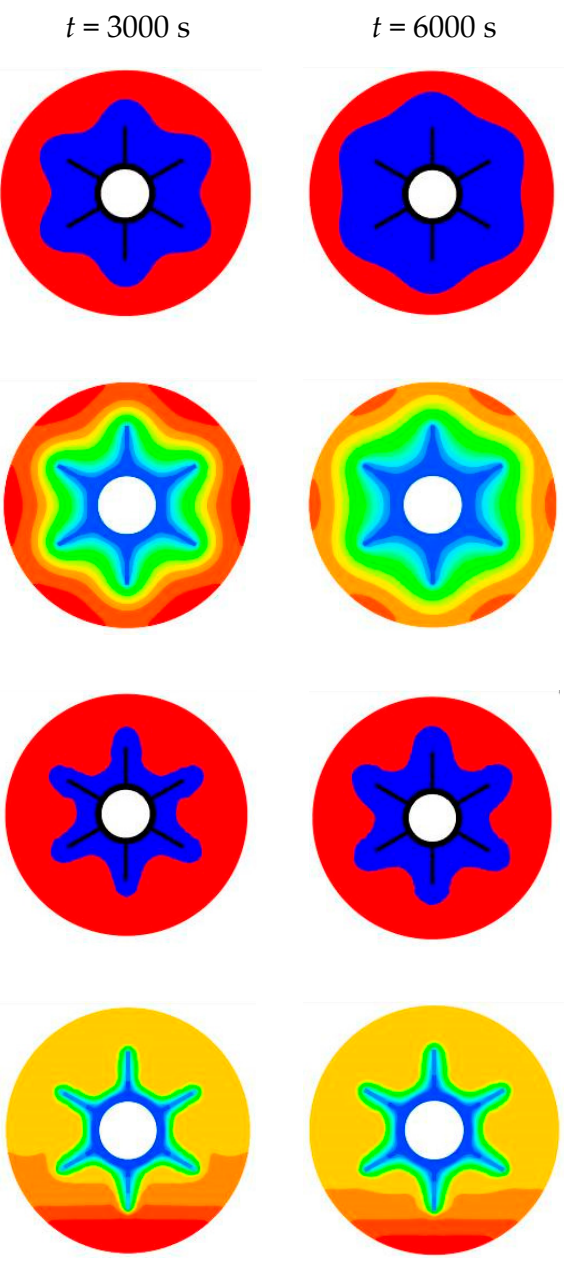
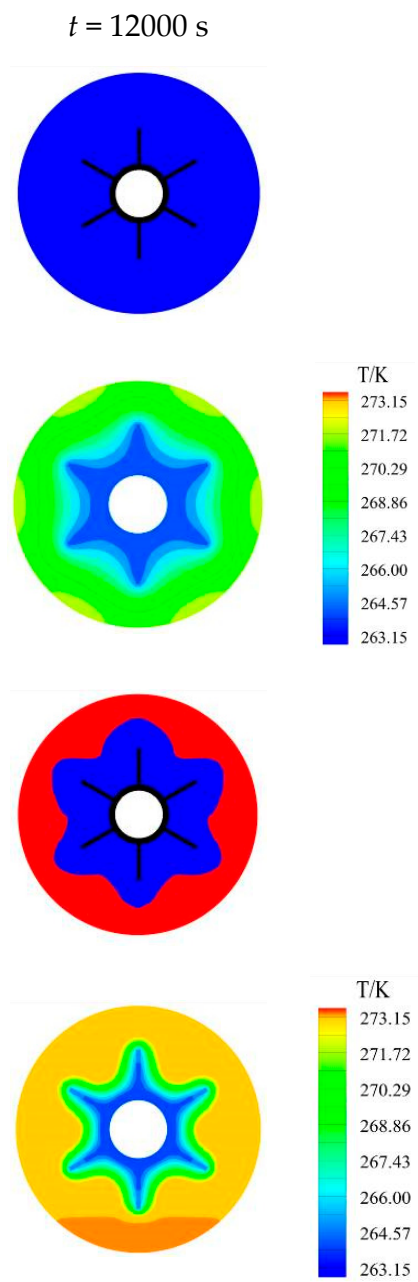

Figure 3. The solidification process in the STIS device with longitudinal fins $(H=30 \mathrm{~mm}, \Delta=3 \mathrm{~mm}$, $N=6$ ). (a) Contours of the liquid fraction without the natural convection $(\mathrm{NC}) ;(\mathbf{b})$ temperature distribution without the NC; (c) contours of the liquid fraction with the NC; (d) temperature distribution with the NC.

\subsection{Influence of the Fin Height}

To explore the influence of the fin height in this simulation, Figure 4 presents contours of the liquid fraction for the STIS device with the six fins $(H=20,30$ or $40 \mathrm{~mm}, \Delta=3 \mathrm{~mm})$. As shown in the figure, the evolution of the liquid fraction is strongly affected by the fin height. With larger fin height, the heat exchange area increases, resulting in an enhanced heat transfer along the radial direction. Furthermore, resulting from the larger fin height, the flow of the water is confined, and thus the NC is weakened. Therefore, the solidification of the water in the STIS device with larger fin height is faster.

To analyze in detail the impact of the fin height for the STIS device with the longitudinal fins, the temperature and streamline distributions in the STIS device with different fin heights at time $3000 \mathrm{~s}$ are shown in Figure 5. The streamlines show the directions in which a massless fluid element will travel at any point in time. With a larger fin height, the water temperature is lower and the vortex flow is weaker. Thus, the solidification of the water is faster, resulting from the weakened NC. 


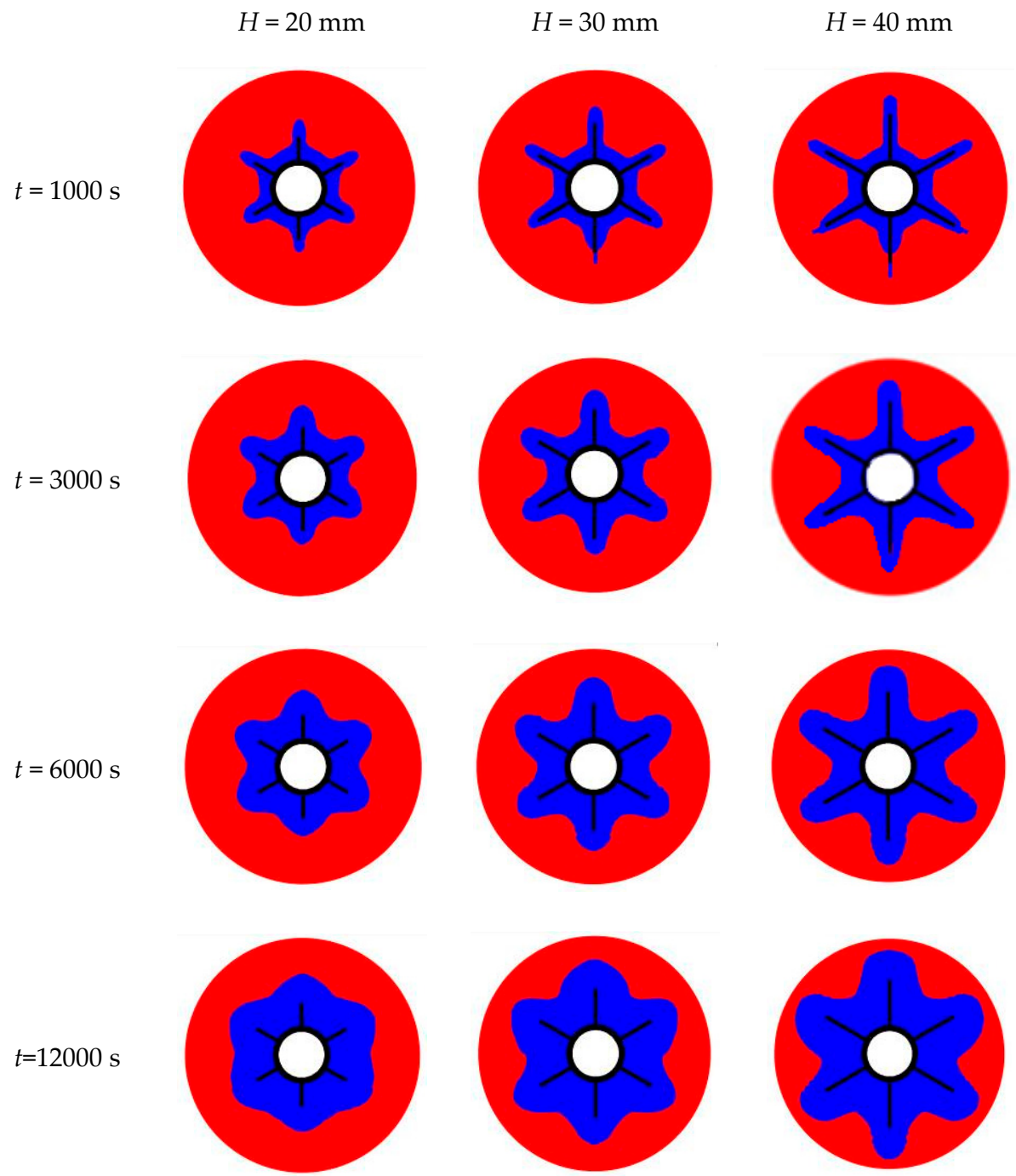

Figure 4. Role of the fin height on the contours of the liquid fraction in the STIS device with the longitudinal fins $(N=6, \Delta=3 \mathrm{~mm})$.

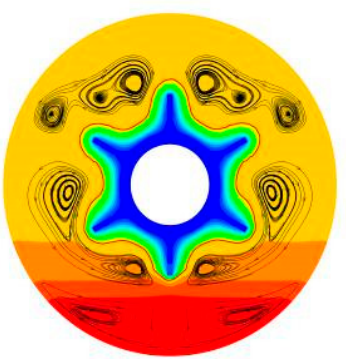

(a)

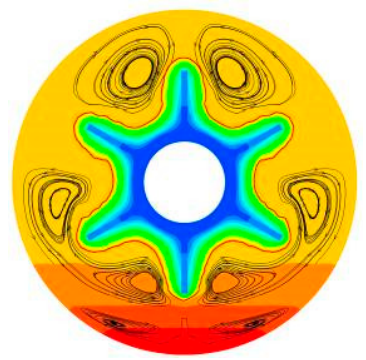

(b)

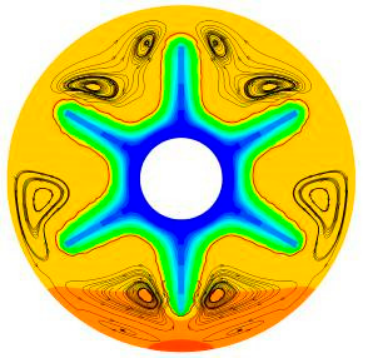

(c)

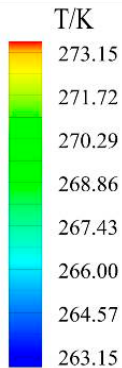

263.15

Figure 5. Influence of the fin height on the distribution of the temperature and the streamline in the STIS device with longitudinal fins at $t=3000 \mathrm{~s}(N=6, \Delta=3 \mathrm{~mm})$. (a) $H=20 \mathrm{~mm}$; (b) $H=30 \mathrm{~mm}$; (c) $H=40 \mathrm{~mm}$.

To better evaluate the enhancement of the ice storage performance by the fin height, Figure 6 shows the energy-discharging rate, the ice storage ratio and the enhanced ratio of the STIS device with three fin heights as a function of time. The enhanced ratio $F$, which is used to evaluate the enhancement of the increase in fin area, is defined as:

$$
F=\eta / n
$$


where $n$ is the ratio between the total area of the optimized fins and that of the smallest fins $(H=20 \mathrm{~mm}$, $N=6, \Delta=1 \mathrm{~mm}$ ). The energy-discharging rate is initially larger due to the large temperature gradient. Then it decreases owing to the decreasing gradient of the water temperature and the increasing thickness of the ice. With a larger fin height, the larger energy-discharging rate indicates a better ice storage performance, resulting in a larger ice storage ratio. As shown in Figure $6 c$, the enhanced ratio decreases as the fin height increases. However, the difference between the enhanced ratios with different fin heights is nearly stable as time progresses.

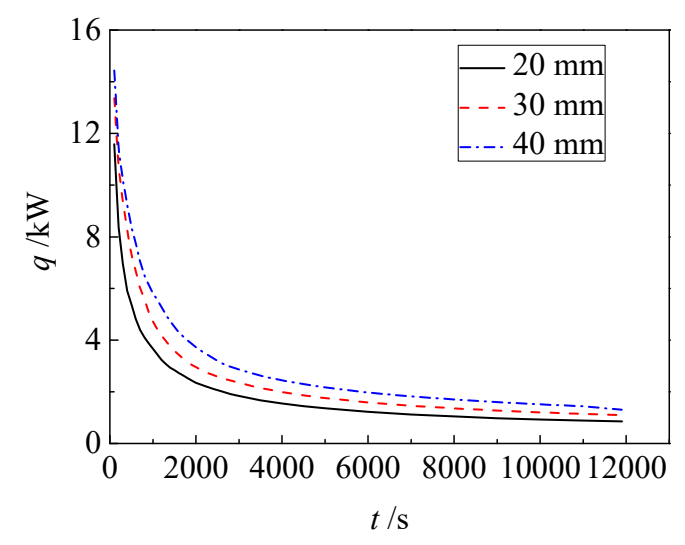

(a)

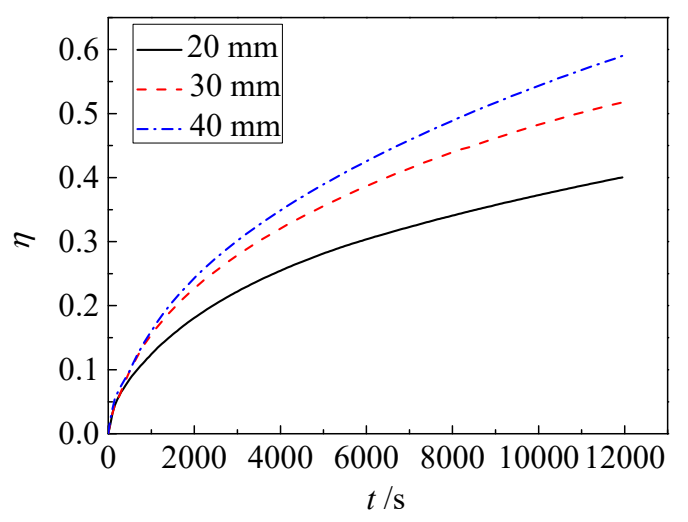

(b)

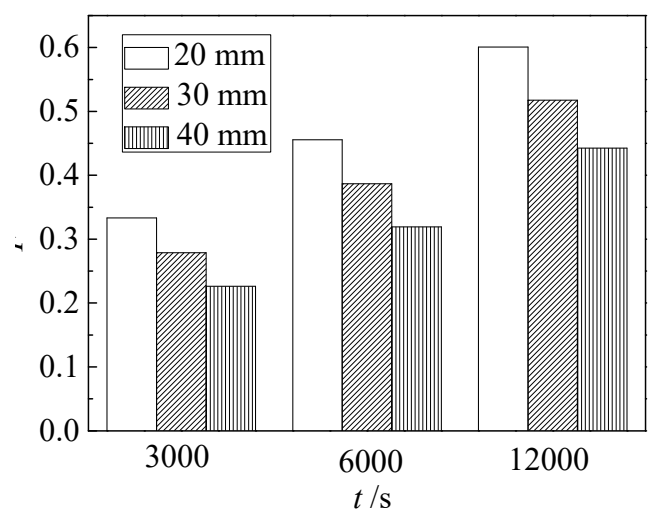

(c)

Figure 6. Role of the fin height in the ice storage performance: (a) energy-discharging rate; (b) ice storage ratio; (c) enhanced ratio $(N=6, \Delta=3 \mathrm{~mm})$.

\subsection{Influence of Fin Thickness}

To discuss the role of the fin thickness for the STIS device, the contours of the liquid fraction for the STIS device with six fins $(H=30 \mathrm{~mm}, \Delta=1,3$ or $5 \mathrm{~mm}$ ) is represented in Figure 7 . As shown in the figure, the evolution of the liquid fraction exhibits different trends with different fin height at the beginning of the solidification process. It can be attributed to the fact that at the initial stage of the solidification process, the thickness of the ice is small. Hence, at this moment, the solidification process is mainly dominated by the heat transfer via the fins. The heat exchange area increases with larger fin thickness, leading to the enhancement of the heat transfer along the radial direction. After the beginning of the solidification process, the thermal resistance induced by the thick ice layer is larger. Hence, the solidification is dominated by the heat transfer near the water-ice interface. Therefore, the solidification of the water in the STIS device with larger fin thickness is faster initially, and enhancement of thicker fins on the solidification becomes less obvious as time goes on. 


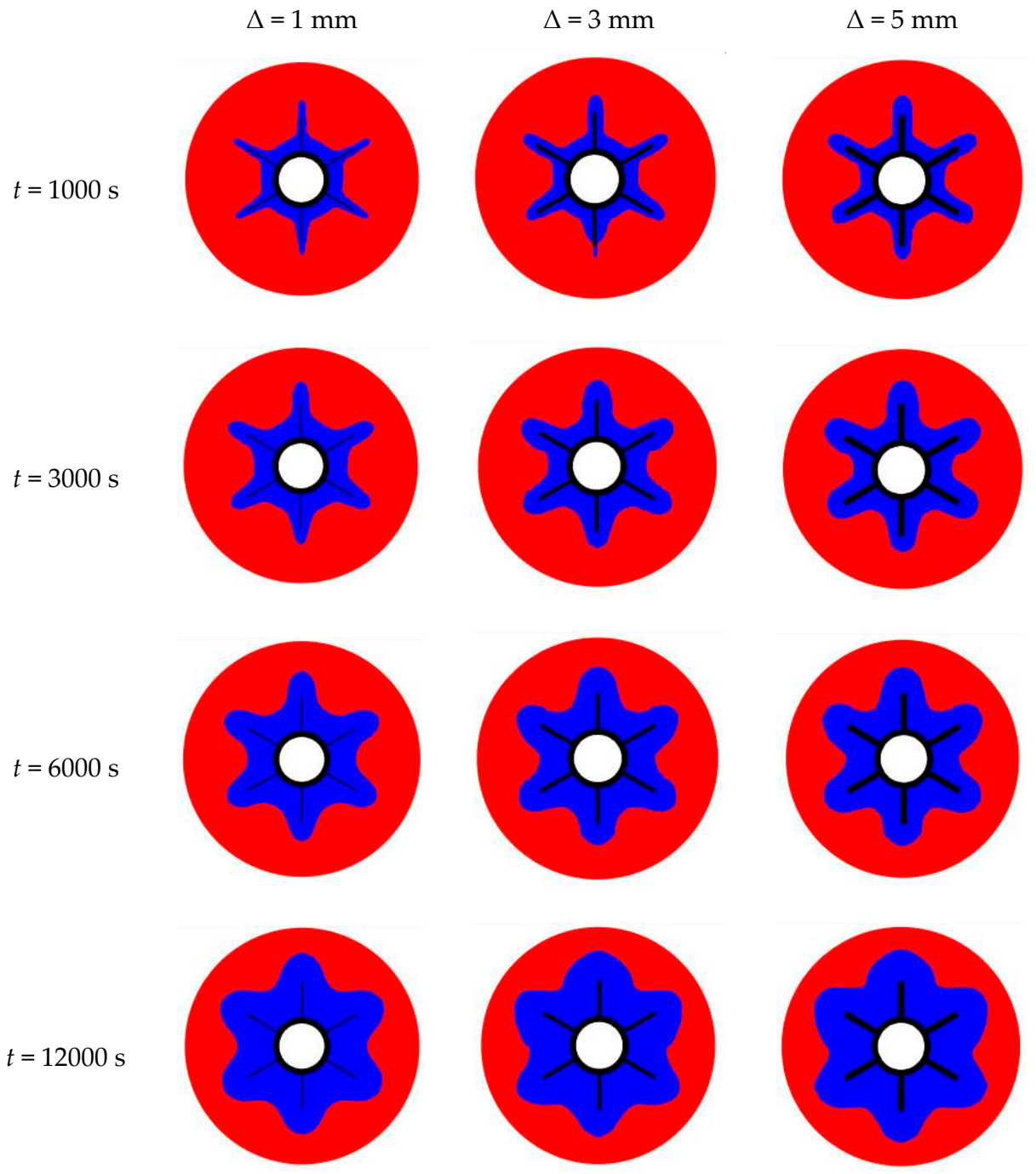

Figure 7. Role of the fin thickness on the liquid fraction in the STIS device with longitudinal fins $(N=6$, $H=30 \mathrm{~mm})$.

To further discuss the role of the fin thickness for the STIS device with the longitudinal fins, the temperature and streamline distributions in the STIS device with different fin thicknesses at time $3000 \mathrm{~s}$ are shown in Figure 8. With a thicker fin, the temperature of the water is lower, resulting from the enhanced cold storage performance. Especially as the fin thickness increases from 1 to $3 \mathrm{~mm}$, the enhanced heat transfer performance is evident.

To evaluate the effect of the fin thickness, the energy-discharging rate, the ice storage ratio and the enhanced ratio of the STIS device with different fin thicknesses are presented in Figure 9. Before time $2000 \mathrm{~s}$, the energy-discharging rate with a thicker fin is larger. After time $2000 \mathrm{~s}$, the energy-discharging curves collapsed with each other, indicating that the influence of the fin thickness is not strong after that time. In addition, as seem from Figure $9 \mathrm{~b}$, there is small difference between the ice storage ratios for the fin thicknesses of 3 and $5 \mathrm{~mm}$. As presented in Figure $9 \mathrm{c}$, the enhanced ratio for the fin thickness of $1 \mathrm{~mm}$ is much larger than the enhanced ratios for the other two fin thicknesses. Further, the difference becomes larger as time goes on. Therefore, increasing the fin thickness is not recommended for enhancing the solidification process. 


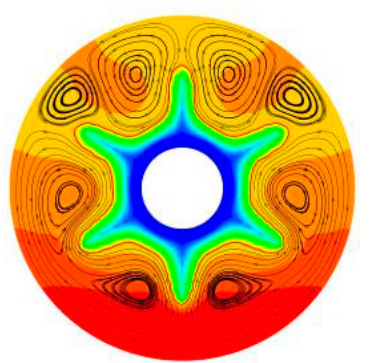

(a)

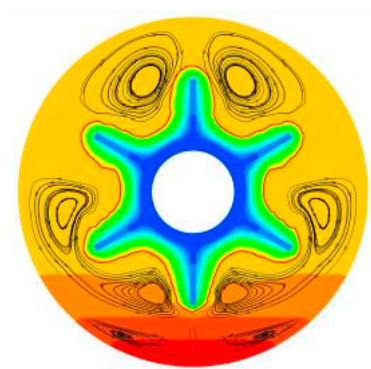

(b)

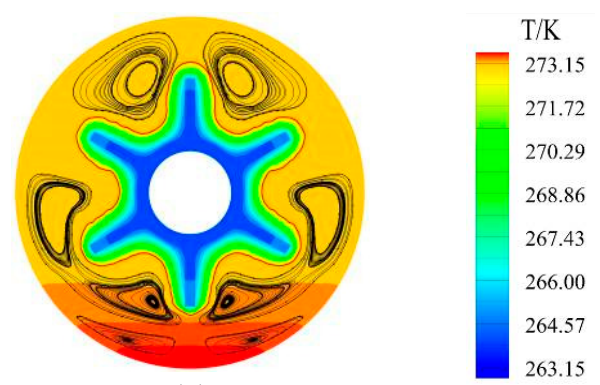

(c)

Figure 8. Role of the fin thickness on the distribution of the temperature and the streamline in the STIS device with longitudinal fins at $t=3000 \mathrm{~s}(N=6, H=30 \mathrm{~mm})$ : (a) $\Delta=1 \mathrm{~mm}$; (b) $\Delta=3 \mathrm{~mm}$; (c) $\Delta=5 \mathrm{~mm}$.

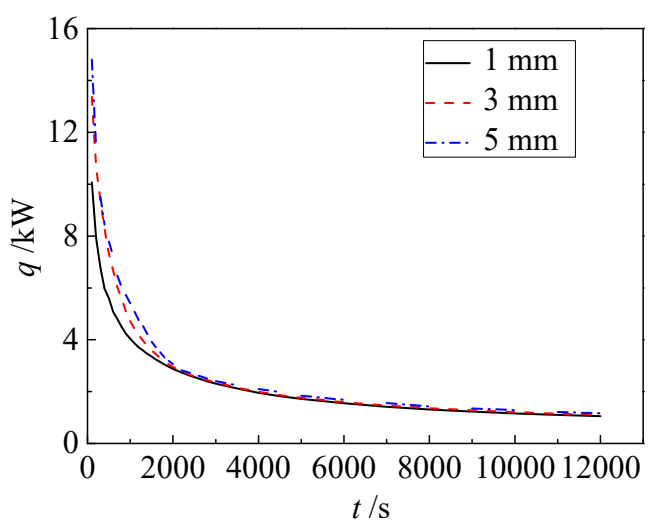

(a)

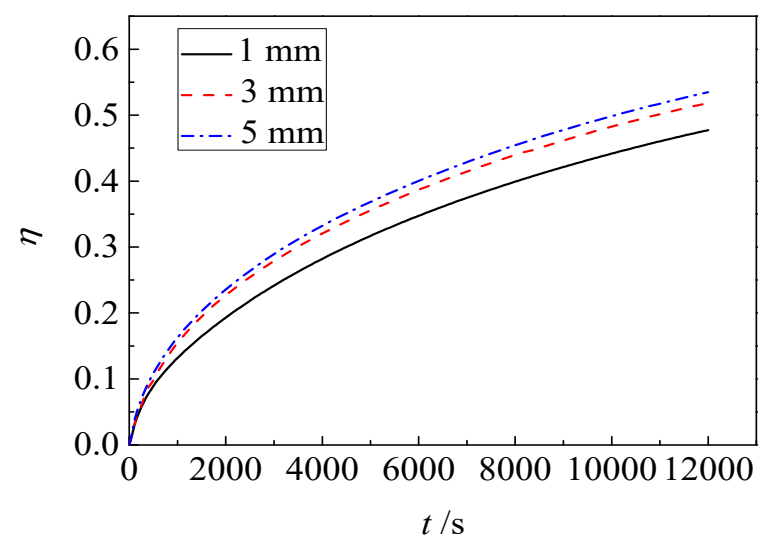

(b)

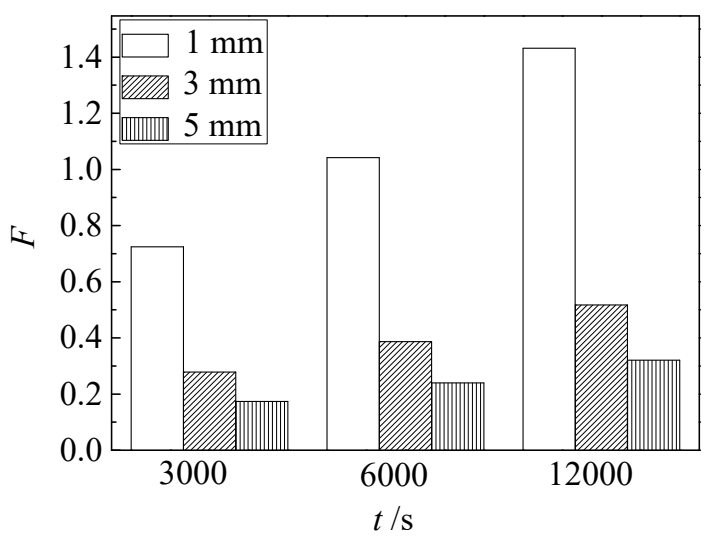

(c)

Figure 9. Role of the fin thickness on the ice storage performance $(N=6, H=30 \mathrm{~mm})$ : (a) energydischarging rate; (b) ice storage ratio; (c) enhanced ratio.

\subsection{Influence of the Fin Number}

To explore the role of the fin number in the solidification process, Figure 10 presents the contours of the liquid fraction for the STIS device with 6,8 or 10 fins $(H=30 \mathrm{~mm}, \Delta=3 \mathrm{~mm})$. As shown in the figure, attributing to the increasing fin number and the increasing heat exchange area, the ice area significantly increases. After that, with the increasing ice thickness, the solidification is dominated by the heat transfer at the water-ice interface and becomes slower. Furthermore, the liquid fraction tends to be a circle, indicating the uniformity of the ice storage. 


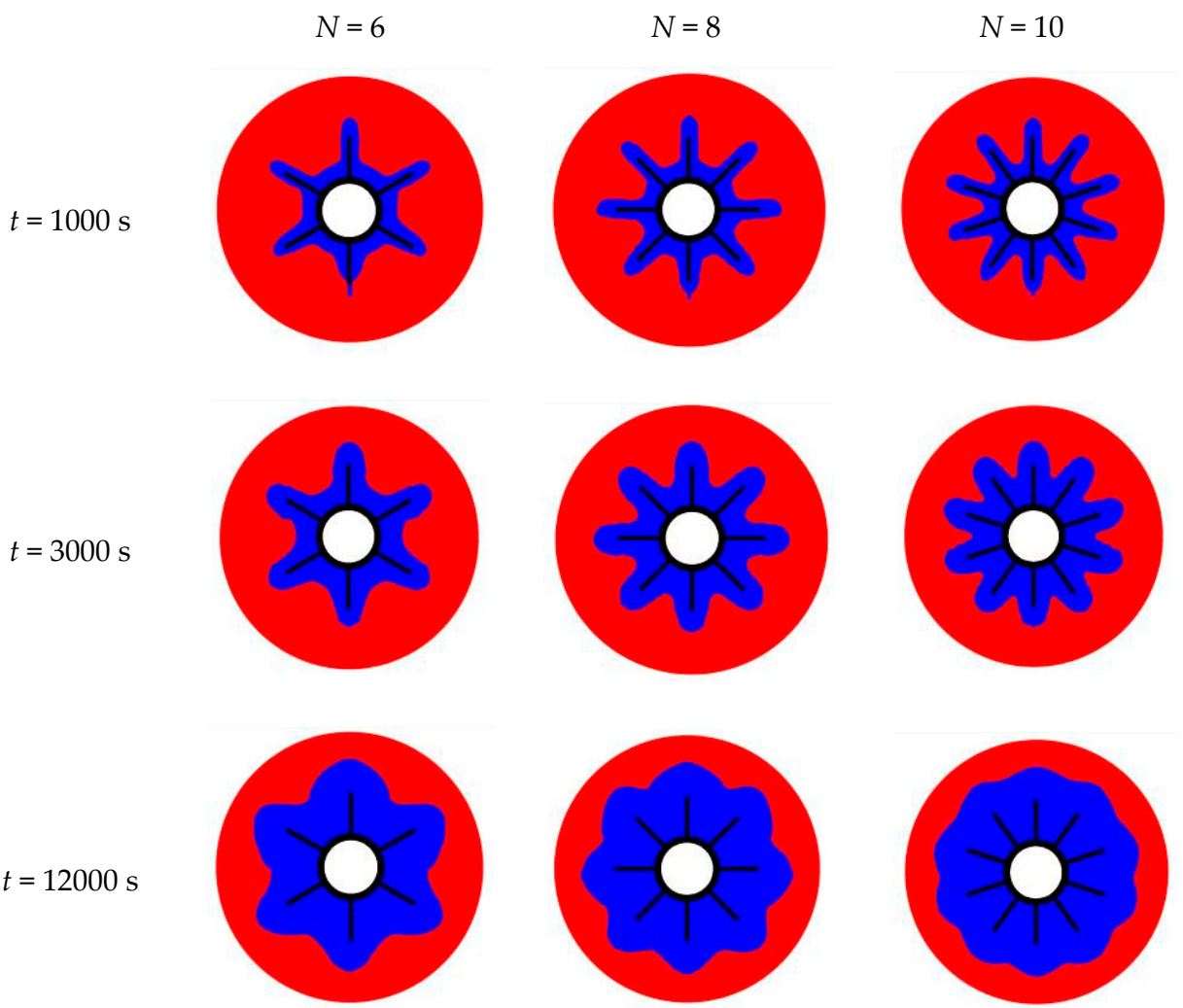

Figure 10. Role of the number of the fins on the contours of the liquid fraction during the ice freezing process of the STIS device with longitudinal fins $(\Delta=3 \mathrm{~mm}, H=30 \mathrm{~mm})$.

The temperature and streamline distributions in the STIS device with different fin numbers at time $3000 \mathrm{~s}$ are shown in Figure 11 so as to investigate in detail the role of the fin number on the solidification process. With more fins, the STIS device is divided into more parts. Thus, there are more but smaller vortexes. Therefore, the NC is effectively weakened, and the solidification process is faster.

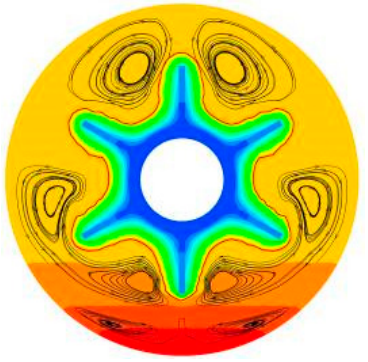

(a)

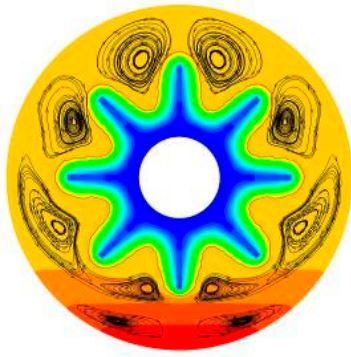

(b)

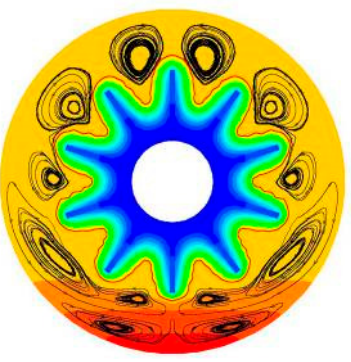

(c)

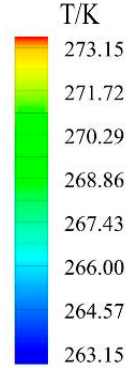

263.15

Figure 11. Role of the fin number on the distribution of the temperature and the streamline in the STIS device at $t=3000 \mathrm{~s}(\Delta=3 \mathrm{~mm}, H=30 \mathrm{~mm})$ : (a) $N=6$; (b) $N=8$; (c) $N=10$.

To better evaluate the ice storage performance enhancement by the increasing fin number, the time evolution of the energy-discharging rate, the ice storage ratio and the enhanced ratio of the STIS device with different fin numbers are illustrated in Figure 12. There is a low energy-discharging rate after time $t=8000 \mathrm{~s}$. It can be explained by the fact that the ice front morphology is beyond the fins, and the solidification is dominated by the heat transfer at the ice-water interface. As a consequence, both the energy-discharging rate and the increasing rate of the ice storage ratio are stable. As shown in Figure 12c, the enhanced ratio also decreases as the fin height increases. Furthermore, the difference between the enhanced ratios with different fin heights increases as time progresses. 


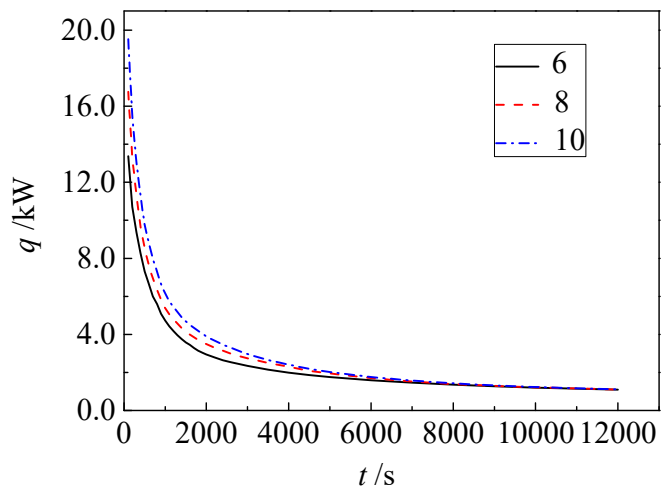

(a)

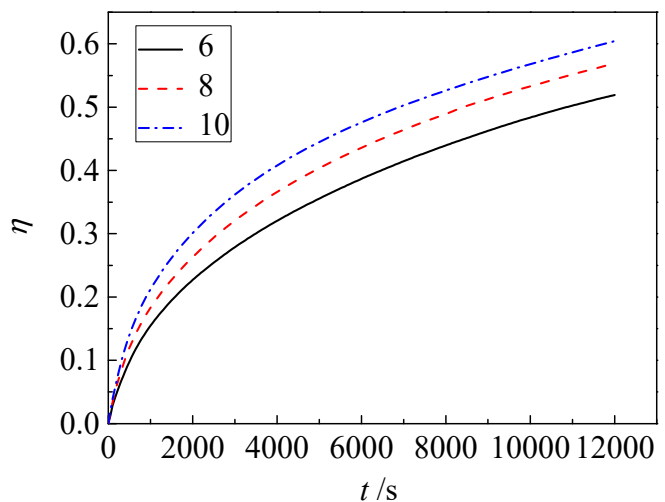

(b)

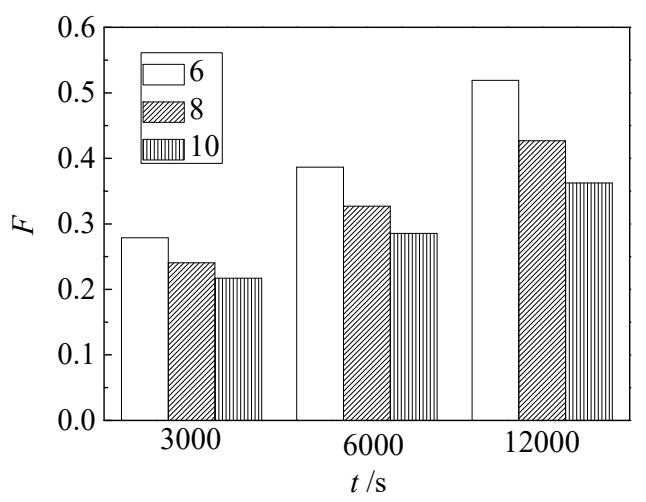

(c)

Figure 12. Role of the fin number in the ice storage performance: (a) energy-discharging rate; (b) ice storage ratio; (c) enhanced ratio. $(H=30 \mathrm{~mm}, \Delta=3 \mathrm{~mm})$.

\section{Conclusions}

The solidification process of an STIS device was simulated in this paper. The liquid fraction, the energy-discharging rate and the ice storage ratio as a function of time were investigated, with a particular focus on the effects of the fin structure parameters on the solidification process. Furthermore, the temperature and the streamline distributions were discussed to reveal the mechanism of the solidification process in the STIS device with longitudinal fins and the negative effect of NC. The conclusions can be summarized as follows:

(1) The solidification process is fast at the initial stage and slows down due to the increasing thickness of the ice. The dominating factor of the ice freezing process is the heat transfer via the fins at the beginning, and then the heat transfer at the water-ice interface.

(2) The ice storage is negatively affected by the NC, because the water with a higher temperature stays in the lower part of the STIS device and the temperature gradient at the water-ice interface is small.

(3) With longitudinal fins, the ice storage area is divided into several parts, resulting in the restriction of the flow and weaker vortex flow. Therefore, the NC can be weakened by the fins.

(4) The ice storage performance can be enhanced by increasing the fin structure parameters, including the height, the thickness and the number. Among these methods, increasing the fin height is the most effective on weakening the $\mathrm{NC}$, which can last for a longer time. The enhancement by increasing the thickness or the number of the fins is obvious at the beginning. Considering the fin area, the increase of fin number is highly recommended for the enhancement of the ice storage performance. 
Author Contributions: Supervision, F.Y. and Y.Z.; methodology, L.W.; validation, P.C. (Peng Cao) and P.C. (Pei Cai); writing - original draft preparation, H.W. and Y.J. All authors have read and agreed to the published version of the manuscript.

Funding: This research was funded by National Natural Science Foundation of China (grant no. 51906170 and 51706194) and the Natural Science Foundation of the Jiangsu Higher Education Institutions of China (grant no. 19KJB470008).

Conflicts of Interest: The authors declare no conflict of interest.

\section{References}

1. Yan, C.; Shi, W.; Li, X.; Zhao, Y. Optimal design and application of a compound cold storage system combining seasonal ice storage and chilled water storage. Appl. Energy 2016, 171, 1-11. [CrossRef]

2. Song, X.; Zhu, T.; Liu, L.; Cao, Z. Study on optimal ice storage capacity of ice thermal storage system and its influence factors. Energ Convers. Manag. 2018, 164, 288-300. [CrossRef]

3. Mousavi Ajarostaghi, S.S.; Poncet, S.; Sedighi, K.; Aghajani Delavar, M. Numerical modeling of the melting process in a shell and coil tube ice storage system for air-conditioning application. Appl. Sci. 2019, 9, 2726. [CrossRef]

4. Pathak, S.; Jain, K.; Kumar, P.; Wang, X.; Pant, R.P. Improved thermal performance of annular fin-shell tube storage system using magnetic fluid. Appl. Energy 2019, 239, 1524-1535. [CrossRef]

5. Mammoli, A.; Robinson, M. Numerical analysis of heat transfer processes in a low-cost, high-performance ice storage device for residential applications. Appl. Therm. Eng. 2018, 128, 453-463. [CrossRef]

6. Sun, L.; Li, G.; Hua, Q.S.; Jin, Y. A hybrid paradigm combining model-based and data-driven methods for fuel cell stack cooling control. Renew. Energy 2020, 147, 1642-1652. [CrossRef]

7. Song, X.; Liu, L.; Zhu, T.; Chen, S.; Cao, Z. Study of economic feasibility of a compound cool thermal storage system combining chilled water storage and ice storage. Appl. Therm. Eng. 2018, 133, 613-621. [CrossRef]

8. Li, Y.; Yan, Z.; Yang, C.; Guo, B.; Yuan, H.; Zhao, J.; Mei, N. Study of a coil heat exchanger with an ice storage system. Energies 2017, 10, 1982.

9. Sun, L.; Shen, J.; Hua, Q.S.; Lee, K.Y. Data-driven oxygen excess ratio control for proton exchange membrane fuel cell. Appl. Energ 2018, 231, 866-875. [CrossRef]

10. Ma, X.; Sheikholeslami, M.; Jafaryar, M.; Shafee, A.; Nguyen-Thoi, T.; Li, Z. Solidification inside a clean energy storage unit utilizing phase change material with copper oxide nanoparticles. J. Clean. Prod. 2020, 245, 118888. [CrossRef]

11. Xu, Y.; Ren, Q.; Zheng, Z.-J.; He, Y.-L. Evaluation and optimization of melting performance for a latent heat thermal energy storage unit partially filled with porous media. Appl. Energy 2017, 193, 84-95. [CrossRef]

12. Zhang, C.B.; Yu, C.; Liu, X.D.; Jin, O.; Chen, Y.P. Steady deformation characteristics of double emulsion droplet in shear flow. Acta Phys. Sin. 2016, 65, 204704.

13. Lan, K.; Liu, J.; Li, Z.; Xie, X.; Huo, W.; Chen, Y.; Ren, G.; Zheng, C.; Yang, D.; Li, S.; et al. Progress in octahedral spherical hohlraum study. Matter Radiat. Extrem. 2016, 1, 8-27. [CrossRef]

14. Ndraha, N.; Hsiao, H.-I.; Vlajic, J.; Yang, M.-F.; Lin, H.-T.V. Time-temperature abuse in the food cold chain: Review of issues, challenges, and recommendations. Food Control 2018, 89, 12-21. [CrossRef]

15. Lo, C.-C.; Tsai, S.-H.; Lin, B.-S. Ice storage air-conditioning system simulation with dynamic electricity pricing: A demand response study. Energies 2016, 9, 113. [CrossRef]

16. Hoseini Rahdar, M.; Emamzadeh, A.; Ataei, A. A comparative study on pcm and ice thermal energy storage tank for air-conditioning systems in office buildings. Appl. Therm. Eng. 2016, 96, 391-399. [CrossRef]

17. Wang, J.; Gao, W.; Zhang, H.; Zou, M.H.; Chen, Y.P.; Zhao, Y.J. Programmable wettability on photocontrolled graphene film. Sci. Adv. 2018, 4, eaat7392. [CrossRef]

18. Al-Shannaq, R.; Young, B.; Farid, M. Cold energy storage in a packed bed of novel graphite/pcm composite spheres. Energy 2019, 171, 296-305. [CrossRef]

19. Zhang, C.; Li, J.; Chen, Y. Improving the energy discharging performance of a latent heat storage (lhs) unit using fractal-tree-shaped fins. Appl. Energy 2019, 259, 114102. [CrossRef]

20. Yang, X.; Niu, Z.; Bai, Q.; Li, H.; Cui, X.; He, Y.-L. Experimental study on the solidification process of fluid saturated in fin-foam composites for cold storage. Appl. Therm. Eng. 2019, 161, 114163. [CrossRef] 
21. Li, S.; Dong, B.; Wang, J.; Li, J.; Shen, T.; Peng, H.; Ling, X. Synthesis and characterization of mixed alkanes microcapsules with phase change temperature below ice point for cryogenic thermal energy storage. Energy 2019, 187, 115898. [CrossRef]

22. Chen, Y.; Gao, W.; Zhang, C.; Zhao, Y. Three-dimensional splitting microfluidics. Lab. Chip 2016, 16, 1332-1339. [CrossRef] [PubMed]

23. Lohrasbi, S.; Sheikholeslami, M.; Ganji, D.D. Multi-objective rsm optimization of fin assisted latent heat thermal energy storage system based on solidification process of phase change material in presence of copper nanoparticles. Appl. Therm. Eng. 2017, 118, 430-447. [CrossRef]

24. Yan, C.; Shi, W.; Li, X.; Wang, S. A seasonal cold storage system based on separate type heat pipe for sustainable building cooling. Renew. Energy 2016, 85, 880-889. [CrossRef]

25. Liu, X.; Chen, Y.; Shi, M. Dynamic performance analysis on start-up of closed-loop pulsating heat pipes (clphps). Int. J. Therm. Sci. 2013, 65, 224-233. [CrossRef]

26. Zhao, D.; Tan, G. Numerical analysis of a shell-and-tube latent heat storage unit with fins for air-conditioning application. Appl. Energy 2015, 138, 381-392. [CrossRef]

27. Hosseini, M.J.; Ranjbar, A.A.; Rahimi, M.; Bahrampoury, R. Experimental and numerical evaluation of longitudinally finned latent heat thermal storage systems. Energ Build. 2015, 99, 263-272. [CrossRef]

28. Pandiyarajan, V.; Chinna Pandian, M.; Malan, E.; Velraj, R.; Seeniraj, R.V. Experimental investigation on heat recovery from diesel engine exhaust using finned shell and tube heat exchanger and thermal storage system. Appl. Energy 2011, 88, 77-87. [CrossRef]

29. Mosaffa, A.H.; Talati, F.; Basirat Tabrizi, H.; Rosen, M.A. Analytical modeling of pcm solidification in a shell and tube finned thermal storage for air conditioning systems. Energ Build. 2012, 49, 356-361. [CrossRef]

30. Longeon, M.; Soupart, A.; Fourmigué, J.-F.; Bruch, A.; Marty, P. Experimental and numerical study of annular pcm storage in the presence of natural convection. Appl. Energy 2013, 112, 175-184. [CrossRef]

31. Seddegh, S.; Joybari, M.M.; Wang, X.; Haghighat, F. Experimental and numerical characterization of natural convection in a vertical shell-and-tube latent thermal energy storage system. Sustain. Cities Soc. 2017, 35, 13-24. [CrossRef]

32. Bo, L.; Zhanwen, Z.; Zhibing, H.; Dangzhong, G.; Sufen, C.; Xiaoshan, H.; Xuesen, Z.; Xiaobo, Q.; Yiyang, L.; Zongwei, W.; et al. Preparation and characterization of inertial confinement fusion capsules. High Power Laser Part. Beams 2015, 27, 032024.

33. Zhao, C.Y.; Lu, W.; Tian, Y. Heat transfer enhancement for thermal energy storage using metal foams embedded within phase change materials (pcms). Sol. Energy 2010, 84, 1402-1412. [CrossRef]

34. Zhao, C.Y.; Wu, Z.G. Heat transfer enhancement of high temperature thermal energy storage using metal foams and expanded graphite. Sol. Energ Mater. Sol. Cells 2011, 95, 636-643. [CrossRef]

35. Agyenim, F.; Eames, P.; Smyth, M. Heat transfer enhancement in medium temperature thermal energy storage system using a multitube heat transfer array. Renew. Energy 2010, 35, 198-207. [CrossRef]

36. Jmal, I.; Baccar, M. Numerical study of pcm solidification in a finned tube thermal storage including natural convection. Appl. Therm. Eng. 2015, 84, 320-330. [CrossRef]

37. Zheng, J.; Yu, C.; Chen, T.; Yu, Y.; Wang, F. Optimization of the melting performance of a thermal energy storage unit with fractal net fins. Processes 2019, 7, 42. [CrossRef]

38. Brent, A.D.; Voller, V.R.; Reid, K.J. Enthalpy-porosity technique for modeling convection-diffusion phase change: Application to the melting of a pure metal. Numer. Heat Transf. 1988, 13, 297-318. [CrossRef]

39. Liu, X.; Zhang, C.; Yu, W.; Deng, Z.; Chen, Y. Bubble breakup in a microfluidic t-junction. Sci. Bull. 2016, 61, 811-824. [CrossRef]

40. Shmueli, H.; Ziskind, G.; Letan, R. Melting in a vertical cylindrical tube: Numerical investigation and comparison with experiments. Int. J. Heat Mass Transf. 2010, 53, 4082-4091. [CrossRef]

(C) 2020 by the authors. Licensee MDPI, Basel, Switzerland. This article is an open access article distributed under the terms and conditions of the Creative Commons Attribution (CC BY) license (http://creativecommons.org/licenses/by/4.0/). 